istic of berberinium salts, which would here destroy the aromatic character of two pyridine nuclei; but it reduces alkaline ferricyanide, and gives with nitrosodimethylaniline in presence of piperidine a deep purple product (presumably by condensation at $\rightarrow$ ) which affords dimethyl- $p$-phenylenediamine on acid hydrolysis. Reduction of $(V)$ with zine and acetic acid gives a non-quaternary methyloctahydrosempervirine, showing that the basic nitrogen atom is doubly linked, unless a $\mathbf{C}-\mathbf{N}$ bond is ruptured by reduction. This remote possibility has been disproved by effecting the following reactions :

\begin{tabular}{|c|c|c|c|}
\hline $\begin{array}{l}\text { empervirine } \\
\text { ethosulphate }\end{array}$ & $\underset{\mathrm{AcOH}}{\stackrel{\mathrm{Zn}-}{\longrightarrow}}$ & $\begin{array}{l}\text { Methyloctahydro- } \\
\text { sempervirine } \\
\text { m.p. 187-189 }\end{array}$ & $\begin{array}{l}\text { Methyloctahydrosemp- } \\
\text { ervirine benzyloiodide } \\
\text { decomp. } 230^{\circ}\end{array}$ \\
\hline $\begin{array}{l}\text { mpervirine } \\
\text { nzylobromide }\end{array}$ & $\underset{\mathrm{AcOH}}{\stackrel{\mathrm{Zn}}{\longrightarrow}}$ & $\begin{array}{l}\text { Benzyloctahydro- } \\
\text { sempervirine } \\
\text { (gum) }\end{array}$ & $\begin{array}{l}\text { Benzyloctahydrosemp- } \\
\text { ervirine methiodide } \\
\text { m.p. } 255^{\circ}\end{array}$ \\
\hline
\end{tabular}

The final products are manifestly distinct quaternary salts, and it is clear that both nitrogen atoms are involved in these changes.

The formulation (IVa $\leftrightarrow \mathrm{IV} b$ ) implies a high electrical dipole moment for sempervirine. Preliminary observations on a dioxan solution of the difficultly soluble base indicated a value approaching $8 \mathrm{D}$, which we report with all reserve. The details of this and further work will be published elsewhere.

We are indebted to the Department of Scientific and Industrial Research for a maintenance grant (to R. B.).

R. BENTLEY

T. S. Stevens

Chemistry Department,

University, Sheffield. Jan. 28.

Helv. chim. Acta, 31, 588 (1948).

\section{Formation of Chelate Complexes between Thiouracils and Heavy-Metal Salts}

THE precipitation of heavy-metal salts by 6 -benzylthiouracil in aqueous solution was observed some years ago ${ }^{1}$.

We have studied the behaviour of some thiouracils towards salts of metals considered as oligo-elements. Aqueous solutions, saturated at $20^{\circ}$, of the following thiouracils, 6-benzyl-thiouracil (I), 6-phenyl-thiouracil (II), 5,6-trimethylene-thiouracil (III), 5,6-tetramethylene-thiouracil (IV), 6-methyl-thiouracil (V) and 5-benzyl-6-methyl-thiouracil (VI), were successively treated with dilute solutions of the following compounds : cobalt chloride, zine sulphate, ferrous sulphate, manganese sulphate and copper sulphate. Whereas cobalt chloride gave no precipitation, the remaining salts all gave more or less abundant precipitates: zine and iron precipitate about 5 per cent of each thiouracil, manganese 10 per cent, copper almost the whole.

In the case of copper, the composition of the precipitates obtained corresponds to the fixation of one copper atom on every thiouracil molecule; that copper is part of a complex and cannot be detected by the usual reagents. The $p H$ of the filtrates is distinctly acid.

The speed of formation of thiouracil coppercomplexes depends on the nature of the thiouracil involved. Flocculent precipitation is instantaneous with $I$ and II. With III and IV, the solution instantaneously becomes cloudy, but a thorough precipitation requires a couple of hours. With $\mathrm{V}$ and
VI, there is an instantaneous change of colour (from blue to green); but precipitation only begins after a while and lasts twenty-four hours.

The structure of thiouracils suggests the following formula for the chelate complexes:

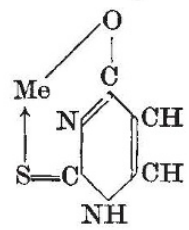

Moreover, we observed for 6-methyl-4-thiouracil the same reaction with copper sulphate as with iodine, following Miller, Roblin and Astwood ${ }^{2}$. An aqueous solution of 6-methyl-4-thiouracil added to a solution of copper sulphate instantly modifies its blue colour into olive-brown. No complex is formed. With gentle heating, a brown flocculent precipitate appears after a while. Precipitation proceeds for quite a long time in the strongly acid filtrate. The precipitate obtained at first does not contain either ionic or concealed copper. It behaves like the disulphide described by Miller et al. and is partly re-transformed into 6-methyl-4-thiouracil by sodium sulphite. The instability of cuprous sulphate explains why the filtrate continues to produce a pre. cipitate after the disulphide has been removed.

The lack of physiological activity of 4-thiouracils is remarkable. On the other hand, Leloup observed some time ago ${ }^{3}$ that administration of active thiouracils to animals reduces cupræmia.

\section{LIBRRMANN}

Research Department,

Établissements Théraplix, 11 rue Gossin,

Montrouge (Seine).

${ }^{1}$ Sonn and Litten, Ber., 66, 1512 (1933).

${ }^{2}$ Miller, Roblin and Astwood, J. Amer. Chem. Soc., 67, 2201 (1946),

${ }^{3}$ Leloup, Bull. Soc. Chim. Biol., 29, 582 (1947).

\section{Oxygen Exchange with Oxides}

As yet few exchange reactions between gases and solids have been reported, and it was suggested to us by Dr. J. S. Anderson that a study of the exchange between oxygen gas and metal oxides might be of interest from the point of view of reactions in the solid state. We give here a preliminary account of the exchange results for oxides of copper $(\mathrm{CuO})$, cobalt $\left(\mathrm{Co}_{3} \mathrm{O}_{4}\right.$ and $\left.\mathrm{CoO}\right)$ and nickel $(\mathrm{NiO})$.

In brief, the experimental technique used was as follows. The oxide under investigation was formed by oxidation of a thin film of the metal deposited electrolytically on a platinum gauze. The oxygen used in this process contained about 1.4 per cent oxygen-18. The exchange was carried out by passing excess of normal oxygen at a definite pressure (above the dissociation pressure) over the heated oxide. At the end of the reaction period the oxide was reduced with hydrogen, and, from the accurate measurement of the density of the sample of water formed, the percentage exchange could be calculated.

The present work is divided into three sections: (i) investigation of the temperature-percentage exchange relation for the oxides mentioned above (see Fig. 1) ; (ii) investigation of the time-percentage exchange relation for the oxide $\mathrm{Co}_{3} \mathrm{O}_{4}$ (see Fig. 2); (iii) investigation of the pressure-percentage exchange 